\title{
Novel Concept in the Mechanism of Injury and Protection of Gastric Mucosa: Role of Renin-Angiotensin System and Active Metabolites of Angiotensin
}

\author{
T. Brzozowski*,1, A. Ptak-Belowska ${ }^{1}$, S. Kwiecien ${ }^{1}$, G. Krzysiek-Maczka ${ }^{1}$, M. Strzalka ${ }^{1}$, D. Drozdowicz ${ }^{1}$, \\ R. Pajdo ${ }^{1}$, R. Olszanecki ${ }^{2}$, R. Korbut ${ }^{2}$, S.J. Konturek ${ }^{1}$ and W.W. Pawlik ${ }^{1}$ \\ ${ }^{1}$ Department of Physiology and ${ }^{2}$ Department of Pharmacology Jagiellonian University Medical College, Cracow, Poland
}

\begin{abstract}
The term cytoprotection pioneered by Robert and colleagues has been introduced to describe the remarkable ability of endogenous and exogenous prostaglandins (PGs) to prevent acute gastric hemorrhagic lesions induced by noxious stimuli such as ethanol, bile acids, hiperosmolar solutions and nonsteroidal anti-inflammatory agents such as aspirin. Since that time many factors were implicated to possess gastroprotective properties such as growth factors including epidermal growth factor (EGF) and transforming factor alpha (TGF $\alpha$ ), vasodilatory mediators such as nitric oxide (NO) and calcitonin gene related peptide (CGRP) as well as appetite gut hormones including gastrin and cholecystokinin (CCK), leptin and recently ghrelin. This protective action of gut peptides has been attributed to the release of PG but question remains whether another peptide angiotensin, the classic component of the systemic and local renin-angiotensin system (RAS) could be involved in the mechanism of gastric integrity and gastroprotection. After renin stimulation, the circulating angiotensin I is converted to angiotensin II (ANG II) by the activity of the Angiotensin Converting Enzyme (ACE). The ANG II acting via its binding to two major receptor subtypes the ANG type 1 (AT1) and type 2 (AT2) has been shown be activated during stress and to contribute to the pathogenesis of cold stress- and ischemia-reperfusion-induced gastric lesions. All bioactive angiotensin peptides can be generated not only in systemic circulation, but also locally in several tissues and organs. Recently the new functional components of RAS, such as Ang-(1-7), Ang IV, Ang-(1-12) and novel pathways ACE2 have been described suggesting the gastroprotective role for the novel ANG II metabolite, Ang-(1-7). The fact that Ang-(1-7) is produced in excessive amounts in the gastric mucosa of rodents and that pretreatment by Ang-(1-7) exhibits a potent gastroprotective activity against the gastric lesions induced by cold-restraint stress suggests that this and possibly other vasoactive metabolites of ANG II pathway could be involved in the mechanism of gastric integrity and gastroprotection. This review summarizes the novel gastroprotective factors and mechanisms associated with metabolic fate of systemic and local RAS activation with major focus to recent advancement in the angiotensin pathways in the gut integrity.
\end{abstract}

Keywords: Gastric protection, renin-angiotensin system, angiotensin-(1-7), Mas receptor, prostaglandin, gastric blood flow, nitric oxide.

\section{GASTRIC MUCOSAL INTEGRITY SYSTEM, CYTOPRO- TECTION AND ADAPTIVE CYTOPROTECTION}

Previous studies have documented that the gastric mucosa of both humans and animals can resist the damage induced by the ingestion of strong topical irritants and ulcerogens [1-3]. This is accomplished by balancing the damaging properties of the corrosive compounds and various stressors with the strengthening effects of the particular lines on the mucosal defense system, thus preventing mucosa injury. The major homeostatic mechanisms involved in the gastric mucosal defense system are the undisturbed gastric mucosal blood flow, the secretion of protective mucus and bicarbonate secretion, the hydrophobic nature of mucosal lining, the generation of protective prostaglandins and the mucosal sulfhydryls within gastric mucosa as well as the vasodilatatory activity of sensory neuropeptides released at the sensory afferent nerve endings. The research that primarily influenced our understanding of the field of gastric mucosal barrier was originally pioneered by C. Code and H. Davenport [1], and was derived from animal studies performed by Andre Robert and his colleagues [2] who proposed the term "cytoprotection". This team described for the first time the unusual features of prostaglandins (PG), the major products of arachidonate metabolism, when given in a non-antisecretory dose, capable of limiting or even completely prevents the gastric mucosal injury induced by strong irritants and corrosive agents [2]. This discovery was at that time a real breakthrough in the field of gastroenterology and shifted the focus of the scientific research of many groups worldwide to search for the compounds that were effective in the prevention of gastric damage independently from the inhibitory effect on gastric acid secretion, which was conventionally believed to play a role in the pathogenesis of peptic ulcer disease. Interestingly, PG applied topically or systemically at

*Address correspondence to this author at the Chairman, Department of Physiology, Jagiellonian University Medical College, 16 Grzegorzecka Street, 31-531 Cracow, Poland; Tel: (+4812) 421-10-06; Fax: (+4812) 422-20-14

E-mail: mpbrzozo@cyf-kr.edu.pl small non-antisecretory concentrations were convincingly effective in the protection of the gastric mucosa exposed to the obnoxious action of not only necrotizing substances such as ethanol, but also hiperosmolar solutions, strong acids (e.g. $0.6 \mathrm{~N} \mathrm{HCl}$ ), bases (e.g. $0.2 \mathrm{~N} \mathrm{NaOH}$ ), concentrated bile, aspirin and even the direct burning effects of boiling water [2-4]. Further detailed studies on the mechanism of action of PG provided the clue for their phenomenal activity by demonstrating that these arachidonate metabolites can increase the gastric microcirculation, stimulate the gastric mucus and bicarbonate secretions, enhance the level of mucosal sulfhydryl compounds and increase the mucosal hydrophobicity [5]. Moreover, PG can directly protect freshly isolated gastric mucosal cells and whole isolated rat and human gastric glands in vitro against gastric injury induced by alcohol or indomethacin, therefore suggesting PG-induced protection independent from vascular, neural and endocrine factors [6-8]. Soon it became clearly evident that certain growth factors, especially EGF, TGF $\alpha$ and bFGF, could be also considered as gastroprotective because they were capable of reducing aspirin-induced gastric ulcerations under conditions where biosynthesis of endogenous PG was completely inhibited by the administration of this NSAID [9].

One of the important forms of cytoprotection is "adaptive cytoprotection", the term that was originally introduced by Robert and his associates (3) to describe the protective activity of endogenous PG generated within the gastric mucosa by mild topical irritants such as $20 \%$ ethanol, $5 \mathrm{mM} \mathrm{NaCl}$ or $5 \mathrm{mM}$ taurocholate in the presence of strong irritants such as $100 \%$ ethanol, $25 \% \mathrm{NaCl}$ or $80 \mathrm{mM}$ taurocholate, known to produce acute hemorrhagic gastric lesions [10]. The concept of cytoprotection pioneered by Robert's experimentation was further extended by the observation that mild irritants afforded a cross-protective response, e.g. 5\% $\mathrm{NaCl}$ was effective in the attenuation of damage induced not only by necrotizing $25 \% \mathrm{NaCl}$ but also by $100 \%$ ethanol, while $20 \%$ ethanol prevented the damage caused by $100 \%$ ethanol or $25 \%$ $\mathrm{NaCl}$ [11]. Moreover, using a bioassay technique to measure the generation of prostacyclin $\left(\mathrm{PGI}_{2}\right)$ and $\mathrm{PGE}_{2}$ in the gastric mucosa, 
Angiotensin I

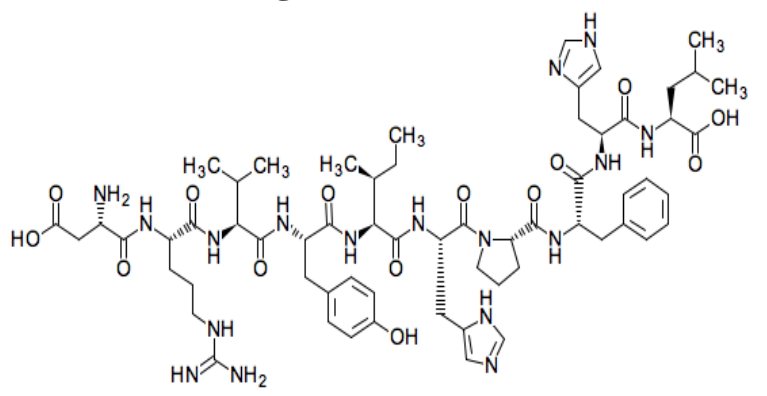

Angiotensin II

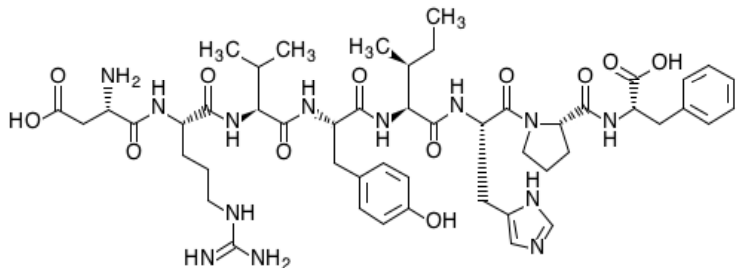

Angiotensin-(1-7)

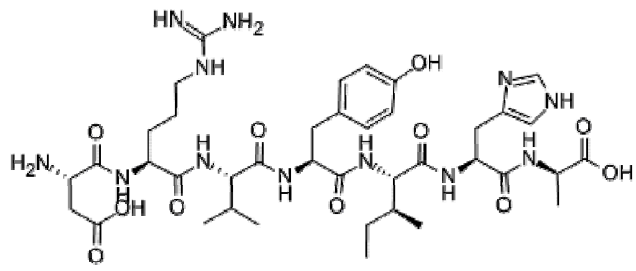

Fig. (1). Chemical structure of major components of RAS system angiotensin I and angiotensin II and the active metabolite of angiotensin II, angiotensin-(17).

our research as well as others revealed that the pretreatment of gastric mucosa with mild irritant resulted in an enhancement of the mucosal generation of $\mathrm{PGI}_{2}$ and $\mathrm{PGE}_{2}$, thus providing direct evidence for the involvement of endogenous PG in the mechanism of adaptive cytoprotection [11-13]. Thus, it was proposed that endogenous PG are involved in protecting the mucosa against the mild irritating damage induced in the stomach by strong irritants applied in higher concentrations, as they protect mainly the proliferative zone of the gastric glands [14,15]. Some other peptides such as cholecystokinin, gastrin, leptin and ghrelin were shown later on to exert gastroprotection [16-21], thus confirming that the ability to protect the gastric lining could not be entirely attributed to PG as initially assumed but might be shared by various peptides and compounds with a non-peptide origin.

\section{FUNCTIONAL COMPONENTS AND SIGNIFICANCE OF RENIN-ANGIOTENSIN SYSTEM (RAS)}

Since the first identification of renin by Tigerstedt and Bergmann in 1898 [22], the renin-angiotensin system (RAS) has been extensively studied. The current view of the system is characterized by an increased complexity, as evidenced by the discovery of new functional components and pathways of the RAS. The octapeptide ANG II was discovered as a circulating prohypertensive principle of renal origin [23]. The activation of RAS remains as a sequential step to the activation of the precursor molecule angiotensinogen. This protein, predominantly synthesized by the liver, is released to the circulation and become cleaved by renin, a circulating enzyme of renal origin and the rate-limiting factor for the system. Due to the action of renin, angiotensin I, an inactive decapeptide is formed. The circulating angiotensin I is then converted to its active principle, angiotensin II (ANG II) by a peptidase, the Angiotensin Converting Enzyme (ACE), which is predominantly located on the surface of lung endothelial cells. Originally, the circulating ANG II was considered the main effector acting via its binding to two major receptor subtypes the ANG type 1 (AT1) and type 2 (AT2) involved in the regulation of blood pressure and body fluid control $[23,24]$. The chemical structure of major RAS peptides Ang I and ANG II as well as the Ang-(1-7), the vasoactive metabolite of ANG II, are presented in Fig. (1).

ANG II, the major effector hormone of RAS, modulates cardiovascular function by inducing vasoconstriction, renal salt and water retention and facilitating sympathetic transmission [25]. In addition, ANG II can induce hypertrophy and/or hyperplasia in the arteries of resistance and cardiomyocytes, thus playing a pathophysiological role in the development and maintenance of hypertension [26]. These effects on the cardiovascular system are clearly mediated by the activation of angiotensin AT 1 receptors [26]. Both AT1 and AT2 receptor subtypes may play a divergent role, because the AT1 receptor is involved in the cell proliferation and the production of cytokines, while the AT2 receptor was reported to regulate the control of blood pressure and to cause the inhibition of cell proliferation, thus contributing to neointimal formation after vascular injury [27]. Some ANG II responses, including NO release and collagen synthesis are mediated by both AT1 and AT2 receptors [28,29]. Both AT1 and AT2 receptor antagonists showed a satisfactory efficacy and safety allowed for widespread use in the treatment of hypertension. Furthermore their anti-inflammatory and vascular protective effects contribute to reduce renal and cardiovascular failure [30,31]. Blockade of the AT1 receptors in humans is also neuroprotective, reducing the incidence of stroke, improving cognition and decreasing the progression of Alzheimer's disease [32], and could be useful in lung disorders such as chronic obstructive pulmonary diseases (COPD) and acute respiratory distress syndrome [33].

\section{ROLE OF RENIN-ANGIOTENSIN (RAS) IN THE MECHANISM OF GASTRIC MUCOSAL INTEGRITY}

Numerous studies have shown that the RAS exerts its endocrine effect on hemodynamic regulation and body fluid homeostasis [34] but less is known about its regulatory impact of the tissue based local RAS, especially in the GI-tract. The existence of local RAS has been demonstrated in a number of organs e.g. brain [32], and gastrointestinal organs including the pancreas, esophagus and colon $[35,36]$. 
The involvement of RAS in the mechanism of gastric integrity and gastroprotection still should be elucidated, but its significance was documented in the pathogenesis of stress, indomethacin and ischemia reperfusion induced gastric damage [36-41]. It is well known that stress induces acute gastric mucosal lesions by complex psychological factors influencing individual vulnerability, stimulation of specific brain pathways regulating autonomic function, decreased blood flow to the mucosa, an increasing muscular contractility and smooth muscle motility, mast cell degranulation, leukocyte activation, and increased free radical generation resulting in increased lipid peroxidation [42,43]. Coldrestraint stress is commonly used and a clinically relevant experimental model for acute gastric damage [44]. A sudden reduction in blood flow to the gastric mucosa and increased free radical formation plays a fundamental role in the production of lesions and erosions that may predispose to ulcer formation [43]. The maintenance of gastric blood flow is important to protect the mucosa from endogenous and exogenous damage factors. ANG II is activated during stress and that the level of this hormone dramatically increases during stress in plasma and peripheral tissues including the stomach [36]. ANG II contributes to the pathogenesis of inflammation induced by various stressors such as ischemiareperfusion and cold stress resulting in acute lesions in the gastric mucosa of rodents $[39,40,45]$. ANG II elicits a cellular response through several molecular signaling pathways, such as calcium mobilization, reactive oxygen metabolite generation, and activation of protein kinase and nuclear transcription factors including nuclear factor $\kappa \mathrm{B}(\mathrm{NF} \kappa \mathrm{B})$ [46-48]. On the other hand, this peptide might contribute to the mucosal defense mechanism via activation of the vascular tone in the arteries of resistance. However, ANG II was shown to not only regulate vascular tone in the arteries of resistance [24] and in the brain tissue [49] but also constricts the gastric vasculature through AT1 receptor stimulation [26]. In addition, ANG II was shown to generate an excessive amount of reactive oxygen species followed by cellular damage and inflammation and to cross-talk with other inflammatory second messengers such as nitric oxide (NO), and PGs through NFKB-dependent mechanism [48,50,51].

The inhibition of ANG II AT1 receptors with peripheral and central receptor antagonists [49] prevents the sympathoadrenal and hypothalamic-pituitary-adrenal response to isolation stress and protects the brain from injury by reducing the cerebral blood flow during a stroke $[45,52]$. The question remains whether antagonism of the AT1 receptors could attenuate the incidence of cold stressinduced gastric lesions and whether AT1 receptor blockade could be of therapeutic usefulness in this stress-related disorder. To address this question, a widely used strain of spontaneously hypertensive rats (SHR) characterized by increased sympathoadrenal reactivity to stress was employed because of the well-known association between stress and cardiovascular disease [36]. In this study, the SHR rats were pretreated with an AT1 receptor blocker before cold-restraint stress. It was found that the AT1 antagonists exhibited the protection against stress-induced gastric lesions due to the suppression of the stress-induced hormonal axis and sympathoadrenal response, the attenuation of the vasoconstrictor effects of ANG II in the gastric microcirculation, thereby causing an inhibition of mucosal inflammation $[36,46,48]$.

There is a growing body of evidence that the components of the renin-angiotensin system (RAS) are present in many organs including the stomach [53], and pancreatic islets [54]. ANG II is a well-known oxidative stress inducer which increases the generation of superoxide anion, hydrogen peroxide and hydroxyl radicals by activating the NADPH oxidase enzyme $[55,56]$. This action is associated with the activation of the inflammatory cascades with increased production of the proinflammatory cytokine, TNF- $\alpha$, which is involved in the pathogenesis of gastric mucosal injury [36].
Since indomethacin-induced acute gastric ulceration is associated with an increased production of TNF- $\alpha$ in the gastric mucosa $[57,58]$, the treatment with telmisartan, the AT1 receptor antagonist, appeared as a good alternative in protection against indomethacin damage [26]. Other mechanisms independent of AT1 receptor blockade are responsible for the antioxidant and antiinflammatory activities of telmisartan, which acts as a partial agonist at the nuclear peroxisome proliferator-activated receptorgamma (PPAR $\gamma$ ) [59]. Activation of this PPAR $\gamma$ receptor system induces catalase gene expression and $\mathrm{NF \kappa B}$, and therefore combating oxidative stress and down-regulating most of the proinflammatory responses $[60,61]$. The study by Morsy et al. [62] documented that rosiglitazone, an agonist of PPAR $\gamma$ receptors significantly protected against indomethacin-induced gastric ulcer in type 2 diabetic rats. The inhibitory effects of telmisartan on gastric lesions could be in part, attributed to its PPAR $\gamma$ agonist activity and the inhibitory action of this AT1 receptor antagonist on the caspase- 3 activation, a proapoptotic system required for the execution of cell apoptosis. It is likely that the antiapoptotic activity of telmisartan depends upon the reduced generation of reactive oxygen species, the inhibition of TNF- $\alpha$ and an increase in NO production as originally indicated $[63,64]$ but seems to be independent from the generation of $\mathrm{PGE}_{2}$ which is suppressed by indomethacin.

The interaction of RAS with the physiology and pathology of the gut has not been extensively studied with respect to Helicobacter pylori (H.pylori), the major pathogen responsible for gastric disorders such as gastritis, ulcer formation and sometimes gastric cancer. Hallesrund et al. [65,66] reported that AT1 and AT2 receptor subtypes are expressed in the gastric wall of Mongolian gerbils and in human gastric mucosa. The subpopulation of endocrine cells within the antral gastric mucosa showed a distinct immunostaining for AT1 receptor [66]. Interestingly, the AT1 receptors were abundant in H.pylori-infected gastric mucosa of Mongolian gerbils and associated with tissue infiltration by neutrophils expressing this receptor [66]. This was in keeping with the previous observations that local RAS is closely associated with inflammation [28]. Recent investigations attempted to look for the expression of AT1 and AT2 receptors as well as the ANG II generating enzymes, namely renin, ACE and neprilysin (NEP) $[65,66]$. It now becomes clear that AT1R and AT2R receptors of principal action ANG II, one of major RAS component, are localized to both gland structures and the surface epithelium, as well to mesenchymal cells and vessels in the lamina propria [66]. Moreover, the human gastric mucosa expresses the proangiotensinogen, renin and ACE suggesting the involvement of RAS in the mechanism of gastric integrity [66]. Similarly as in gerbils, the endocrine cells in the human antral gastric mucosa exhibited the expression of AT1 receptors, and this expression was further potentiated in H.pylori-infected gastric mucosa, with the latter effect being correlated to an increase in neutrophil-infiltrating inflamed gastric mucosa [66]. It is of interest that the rise in the expression of AT1 receptors does not seem to correlate with the number of lymphocytes. This observation was in accordance with the report of Rasini et al. [67] who found that neutrophils in the human blood have the highest AT1 receptor expression among all population of white blood cells investigated. The expression of AT1 receptor could be linked to the increased production of reactive oxygen metabolites (ROM) since Mongolian gerbils infected with H.pylori revealed an increase in the hydrogen peroxide [68]. Constant ROM generated locally in the gastric mucosa in response H.pylori and the release of its bacterial cytotoxins encoding for CagA and VacA might explain the link between gastritis, the gastroduodenal ulcerations and in some cases cancer development in H.pylori-infected individuals [69]. This suggests that the activation of local RAS, the enhanced AT1 receptors and ROM generation affecting gastric microcirculation, which may contribute 
to H.pylori-induced tissue damage and a DNA mutation that predisposes the gastric mucosa to gastric adenocarcinoma [70].

\section{ANG-(1-7) AS ONE OF THE MAJOR VASODILATORY AND PROTECTIVE RAS COMPONENTS IN THE GUT}

Active metabolites of local RAS exhibit a profound physiological effects on the vasculature and therefore could be considered an important component of the gastrointestinal defense system. Using the mesenteric arterial bed (MAB) of normotensive rats, Soares de Moura et al. [71] have demonstrated that ANG II has no vasoconstrictor effect on the resting perfusion pressure, but induces an endothelium-derived relaxing factor (EDRF)-dependent effect when these vessels are preconstricted with noradrenalin (NA). In addition, they provided evidence that this effect seems to be modulated by an interaction with ANG II, bradykinin (BK) and Ang-(1-7) receptors [71]. Recent studies in spontaneously hypertensive rats (SHR) have demonstrated that the contraction induced by ANG II in the isolated aorta and mesenteric arteries is reversed with vasodilatation after chronic treatment with AT1 receptor antagonists [72,73]. The AT2 receptor-mediated vasodilator response could also significantly contribute to the observed beneficial hemodynamic effects of the AT1 receptor blockade. These observations pointed out the role of active metabolites of ANG II such as Ang-(1-7), which is a potent vasodilator compound $[74,75]$ and an endogenous ligand of the specific Mas receptor [76]. The Mas oncogene is a G proteincoupled receptor which binds the ANG II metabolite, Ang-(1-7) [76]. Recent evidence indicates that the Mas receptor when activated by binding Ang-(1-7) opposes many of the effects of ANG II activated angiotensin receptor [76]. Ang-(1-7) could be involved in the mechanism of action of ANG II in rat MAB because both Ang-(1-7) and ANG II-induced a similar vasodilatatory response in the MAB. At a concentration that reduced the vasodilator effect of Ang-(1-7), the A779, a putative Ang-(1-7) antagonist, also reduced the vasodilator effect of ANG II, suggesting a contribution of Ang-(1-7) to the vasodilator effect of ANG II. Further proof of vasodilatory action of Ang-(1-7) was delivered by Oliveira et al. [77] who demonstrated that the Ang-(17) potentiation of bradykinin-induced vasodilatation in rat mesenteric vessels is abolished by NO-synthase inhibitor, LNAME.

These observations significantly changed our understanding of the contribution of RAS to the functioning of particular metabolites in peripheral organs emphasizing the protective role of some of the active metabolites of RAS, in particular ANG II. This notion is based on the fact that the new functional components of RAS, such as Ang-(1-7), Ang IV, Ang-(1-12) and novel pathways ACE2 have been described [78,81] but their role in GI-tract should be investigated. An important observation is that all bioactive angiotensin peptides can be generated not only in systemic circulation, but also locally in several tissues and organs. These peptides acting via autocrine and/or paracrine manner have been described in the kidney, heart, liver, pancreas, adrenal gland, brain, ovaries and testes [82-84]. Indeed, the pretreatment by Ang-(1-7) exhibited a potent gastroprotective activity against the gastric lesions induced by cold-restraint stress in rats [85] and this effect was accompanied by the marked increase in the gastric blood flow that counteracted the fall in flow observed in animals not pretreated with this vasoactive metabolite of ANG II. Moreover, the plasma cytokine IL-1 $\beta$ and TNF- $\alpha$ was significantly increased in stressed animals and this effect was ameliorated in rats pretreated with Ang(1-7) (Fig. 2). In contrast, ANG II administered under the same experimental conditions to stressed rats, exacerbated the coldrestraint gastric lesions and produced a further fall in the gastric blood flow and the significant elevation of plasma IL-1 $\beta$ and TNF$\alpha$ levels as compared to the respective controls (Fig. 2). This finding clearly indicates that endogenous generation of Ang-(1-7) could act as the important protector and vasodilator of the gastric mucosa and further studies should confirm the role of this novel factor and its efficacy in the mechanism of ulcer healing.

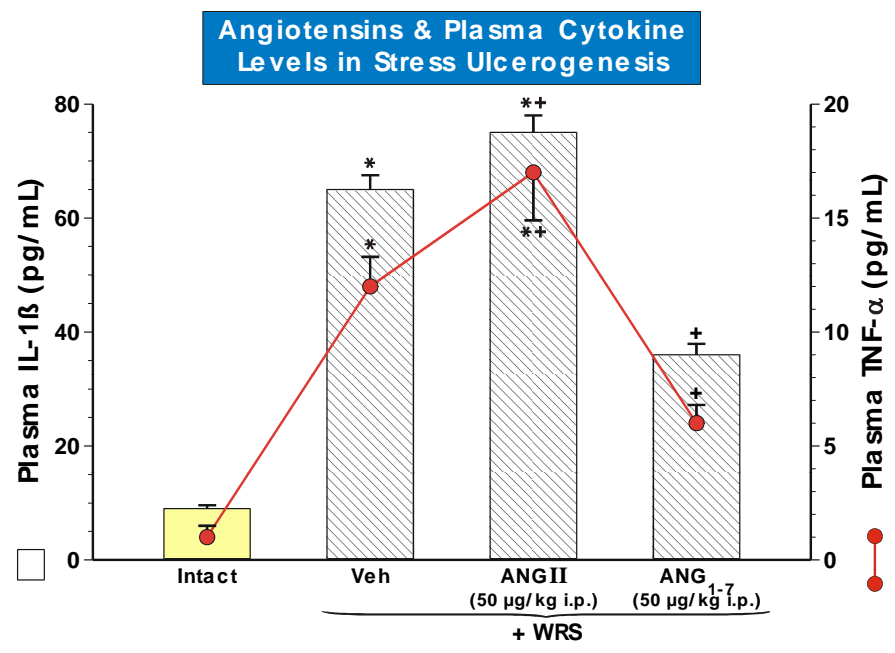

Fig. (2). The effect of pretreatment with Ang-(1-7) and ANG II on the plasma proinflammatory cytokine IL- $1 \beta$ and TNF- $\alpha$ levels during cold stress-induced ulcerogenesis in rats. Ang-(1-7) shows remarkable attenuation of plasma cytokines while the pretreatment with ANG II significantly enhanced the level of IL- $\beta$ and TNF- $\alpha$ in rats exposed to cold stress. Results are mean $\pm \mathrm{SE}$ of 6-8 rats per each experimental group. Asterisk indicates a significant increase $(\mathrm{p}<0.05)$ from intact animals. Asterisk and cross indicate a significant increase $(\mathrm{p}<0.05)$ above the values obtained in rats pretreated with ANG II. Single cross indicates a significant change $(p<0.05)$ from the values obtained in vehicle-control rats and those pretreated with ANG II

ANG II has been implicated in the pathogenesis of gastric lesions [86-88] but the recent evidence indicated that both, ACE and ACE2 involved in Ang I and ANG II conversion pathway are expressed in the gastric mucosa [89,90]. Recently, Olszanecki and colleagues [91] made an important contribution to the field of angiotensin research. Using liquid chromatography and electrospray ionization - mass spectrometry (LC-ESI-MS), they developed an accurate, reproducible and comprehensive method of quantitation of formation of angiotensin peptides in an organ bath of gastric mucosal tissue fragments exposed to exogenous ANG I [90,91] (Fig. 3). This method allowed them to assess the metabolism of Ang I in an organ bath of rat stomach walls [90]. They identified Ang-(1-7) as the main product of Ang I conversion in the rat stomach wall despite that there were apparent discrepancies concerning the Ang I conversion pathways in the stomach, aorta and renal artery [91]. The expression of mRNA for ACE and ACE2 in the stomach and aorta and the overall rate of generation of Ang I metabolites were much lower in the stomach wall but the prevalence of ANG II formation was evidently higher in the aorta, but that of Ang-(1-7) was evidently superior in the gastric mucosa comparing other tissues (Fig. 4). They referred this apparent difference between particular angiotensins Ang I and ANG II to posttranscriptional regulation of enzymes involved in angiotensin metabolism in various organs including the stomach and vascular bed [91] but to confirm that hypothesis detailed studies at the protein level are needed.

Ang-(1-7) could directly originate from Ang I via NEP activity detected in the gastric mucosa as well as indirectly via ANG II (sequential action of ACE then ACE2) or via the formation of Ang(1-9) due to the combined activity of ACE2 and later on ACE. Study by Olszanecki et al. [91] revealed that the gastric formation 


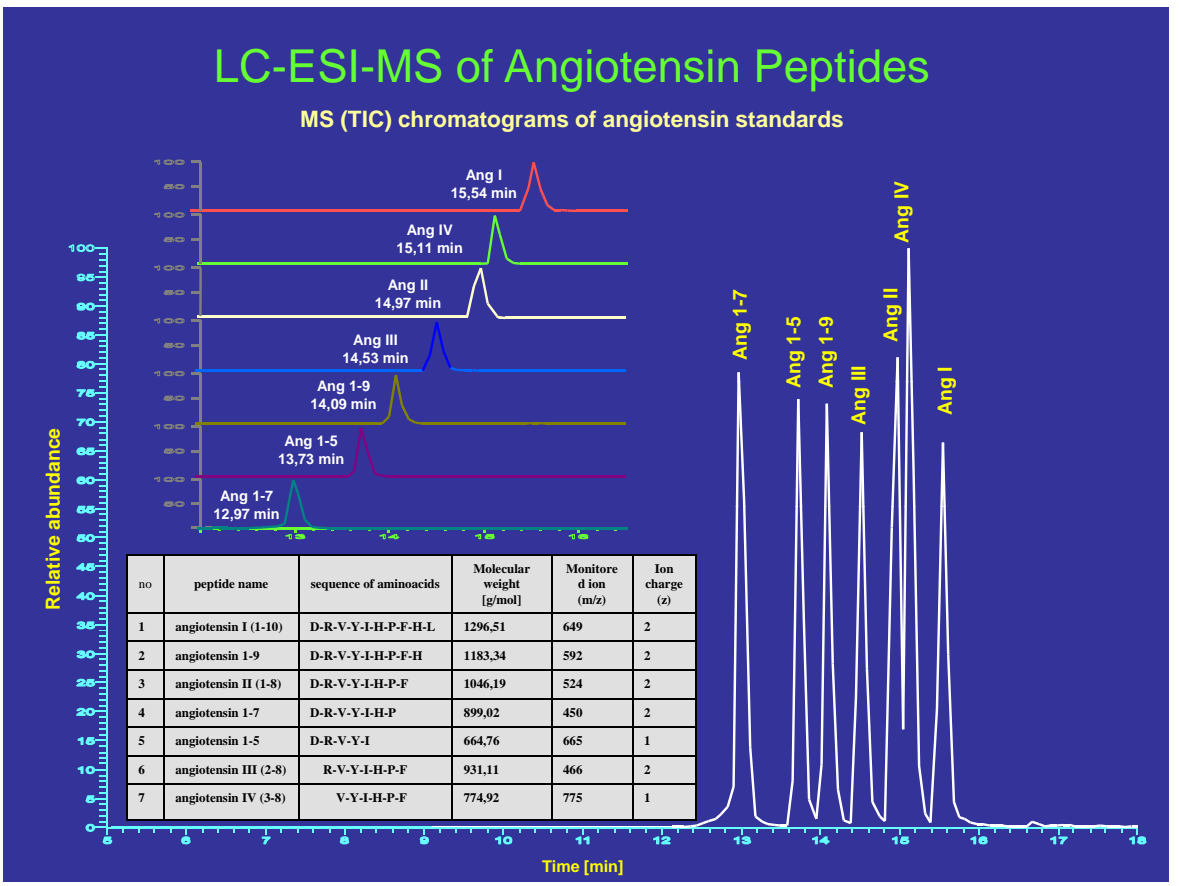

Fig. (3). Chromatogram analysis of angiotensin I, II. III, IV, 1-9, 1-7 and 1-5 standards separated originally by HPLC method followed by Liquid chromatography - Electrospray ionization - Mass spectrometry (LC-ESI-MS) (adapted with permission from Bujak-Gizycka et al. Journal of Physiology and Pharmacology 2007, 58, 3, 529-540).

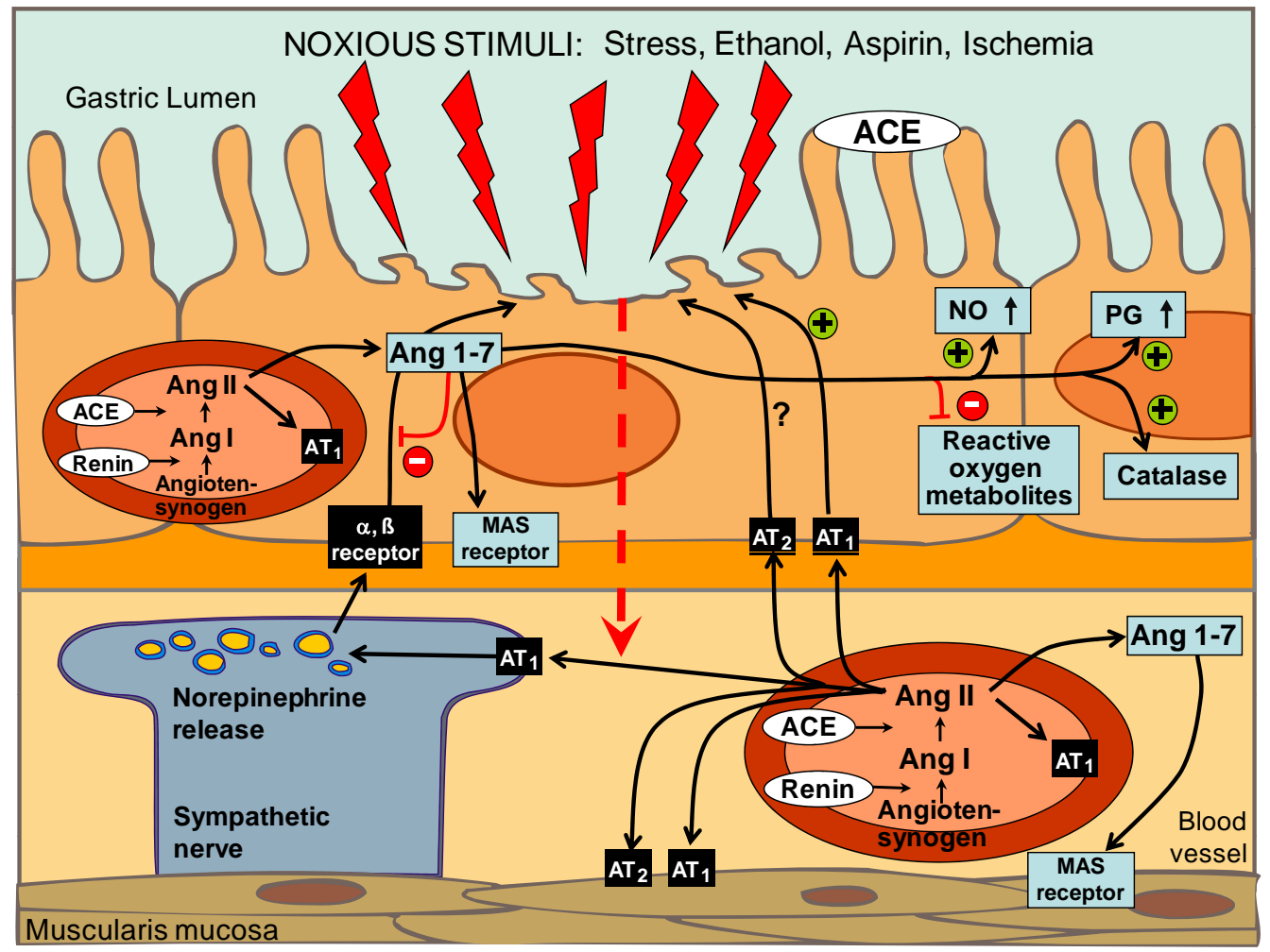

Fig. (4). Proposed scheme of the existence and contribution of systemic and local renin-angiotensin system (RAS) in the gastric mucosa of the stomach exposed to noxious stimuli such as stress, ethanol, aspirin or ischemia. Both systemic and local RAS activation starts from Angiotensin I that is formed from angiotensinogen via the stimulation of renin activity. Angiotensin I is converted into ANG II due to the action of ACE. ANG II give rise to its major metabolite Ang-(1-7) which acts on specific Mas receptor. Injury to the gastric mucosa may trigger the local RAS in the microcirculation of the gastric wall and in the epithelial cells. ANG II activates AT1 and AT2 receptors and contributes to the injury induced by various systemic and topical ulcerogens. In contrast, the active metabolite of ANG II, Ang-(1-7) exhibits a potent gastroprotective action mediated by NO and possibly by endogenous PG system. Ang-(1-7) was recently shown to inhibit the generation of reactive oxygen metabolites and activate the free radical scavenging enzyme, catalase. 
of Ang-(1-7) seems to not depend on the activity of ACE and NEP since the generation of Ang II was completely inhibited by perindoprilat.

\section{SUMMARY}

Prostaglandins were originally considered as a pivotal cytoprotective agents exerting also a profound influence on the process of ulcer healing [92]. More recently other physiological mediators such as salivary growth factors (EGF) and the activity of vagal innervation [93] as well as the vasoreactive compounds (NO and hydrogen sulfide) were implicated in the mechanism of cytoprotection and the process of gastroduodenal ulcer healing. This review sheds some light on the importance of local RAS and Ang-(1-7), acting via the MAS receptor to directly antagonize many actions of ANG II [76,94], thus contributing to the mechanism of gastric integrity and gastroprotection. According to this new concept, RAS can be considered as a dual function system in which the vasoconstrictor and damaging or vasodilatatory and gastroprotective actions are primarily driven by the balance between ACE/Ang II/AT1 receptor and ACE2/Ang-(1-7)/MAS receptor pathways, respectively [94,95] (Fig. 4). It has been recently suggested that part of the beneficial effects of drugs like ACE inhibitors or AT1 receptor blockers may depend on shifting the balance toward ACE-2/Ang-(1-7)/MAS axis [95,96]. This is in keeping with previous observations that ACE inhibitors and AT1 receptor blockers may prevent stress-induced gastric injury [31] suggesting that these protective and hyperemic effects could be mediated, at least in part, by Ang-(1-7) as the main beneficial product of Ang I conversion within the gastric mucosa (Fig. 4). The role of particular components of RAS in more chronic models of experimental gastric ulcer as well as studies on Ang-(1-7) in the human pathophysiology of peptic ulcer disease warrants further investigation.

\section{ACKNOWLEDGEMENTS}

These studies described in this review paper were in part received financial support from the grant N N402 479937 from Polish Ministry of Science and Higher Education in Warsaw, Poland to Dr. Tomasz Brzozowski. Authors would like to express their sincere thanks and appreciation to Mrs. Nily Osman for the critical reading of the manuscript and generous help in the preparation of this work for publication. No potential conflict of interest.

\section{REFERENCES}

[1] Davenport, H.W.; Warner, H.A.; Code, C.F. Functional significance of gastric mucosal barrier to sodium. Gastroenterology, 1968, 4, 709-11.

[2] Robert, A.; Nezamis, J.E.; Lancaster, C.; Hanchar, A.J. Cytoprotection by prostaglandins in rats. Prevention of gastric necrosis produced by alcohol, $\mathrm{HCl}, \mathrm{NaOH}$, hypertonic $\mathrm{NaCl}$ and thermal injury. Gastroenteroligy, 1979, 77, 433-440.

[3] Konturek, S.J.; Piastucki, I.; Brzozowski, T.; Radecki, T.; Dembinska-Kiec, A.; Zmuda, A.; Gryglewski, R. Role of prostaglandins in the formation of aspirin induced gastric ulcers. Gastroenterology, 1981, 80, 4-9.

[4] Konturek, S.J.; Radecki, T.; Brzozowski, T.; Piastucki, I.;, Dembinska-Kiec, A.; Gryglewski, R.. Prostaglandin E2 in gastric mucosa and its role in the prevention of ulcers induced by acetyl salicylic acid in cats. Digestion, 1981, 21, 205-213

[5] Svanes, K.; Gislason, H.; Guttu, K.; Herfjord, J.K.; Fevang, J.; Gronbech, J.E. Role of blood flow in adaptive protection of the cat gastric mucosa. Gastroenterology, 1991, 100, 1249-1258.

[6] Terano, A.; Mach, T.; Stachura, J.; Tarnawsk, A.; Ivey, K.J. Effect of 16,16 dimethyl prostaglandin $\mathrm{E}_{2}$ on aspirin induced damage to rat gastric epithelial cells in tissue culture. Gut, 1984, 25, 19-25.

[7] Tarnawski, A.; Brzozowski, T.; Sarfeh, J.; Krause, W.J.; Ulich, T.R.; Gergely, H.; Hollander, D. Prostaglandin protection of human isolated gastric glands against indomethacin and ethanol injury. Evidence for direct cellular action of prostaglandin. J. Clin. Invest., 1998; 81, 1081-1089.

[8] Brzozowski, T.; Tarnawski, A.; Hollander, D.; Sekhon, S.; Krause, W.J.; Gergely, H. Comparison of prostaglandin and cimetidine in protection of isolated gastric glands against indomethacin injury. J. Physiol. Pharmacol ., 2005, 56, 5: 75-88.

[9] Konturek, S.J.; Brzozowski, T.; Majka, J.; Dembinski, A.; Słomiany, A.; Słomiany, B.L. Transforming growth factor and epidermal growth factor in protection and healing of gastric mucosal injury. Scand. J. Gastroenterol., 1992, 27, 649-655

[10] Robert, A.; Nezamis, I.E.; Lancaste,r C.; Davies, I.P.; Field, S.O.; Hanchar, A.J. Mild irritant prevent gastric necrosis through adaptive cytoprotection mediated by prostaglandins. Am J Physiol 1983, 245: 113-116.

[11] Konturek, S.J.; Brzozowski, T.; Piastucki, I.; Dembinski, A.; DembinskaKiec, A. Role of locally generated prostaglandin in adaptive gastric cytoprotection, Dig. Dis. Sci., 1982, 27: 967-77.

[12] Cho, C.H.; Ko, I.K.; Tang, X.L. The differential mechanism of mild irritants on adaptative cytoprotection. Eur. J. Gastroenterol. Hepatol., 1994, 9, 1, 24.

[13] Mutoh, H.; Ota, S.; Hiraishi, H.; Ivey, K.J.; Terano, A.; Sugimoto, T.; Adaptive cytoprotection in cultured rat gastric mucus-producing cells. Role of mucus and prostaglandin synthesis. Dig. Dis. Sci., 1995; 40, 872-878.

[14] Lacy, E.;R, Ito, S. Microscopic analysis of ethanol damage to rat gastric mucosa after treatment with a prostaglandin. Gastroenterology, 1982, 83, 619-625.

[15] Tarnawski, A.; Hollander D, Stachura J, Krause WJ, Gergely H. Prostaglandin protection of the gastric mucosa against alcohol injury - a dynamic time related process. Role of the mucosal proliferative zone. Gastroenterology, 1985, 88: 334-52.

[16] Konturek, S.;J, Brzozowski, T.; Pytko-Polonczyk, J.; Drozdowicz, D. Exogenous and endogenous cholecystokinin protects gastric mucosa against the damage caused by ethanol in rats. Eur. J. Pharmacol., 1995, 273: 57-62.

[17] Konturek, S.J.; Brzozowski, T.; Bielanski, W.; Schally, A.V. Role of endogenous gastrin in gastroprotection. Eur J Pharmacol 1995, 278, 203212 .

[18] Brzozowski, T. Konturek, P.Ch.; Pajdo, R.; Duda, A.; Pierzchalski, P. Bielanski, W. et al. Leptin in gastroprotection induced by cholecystokinin or by a meal. Role of vagal and sensory nerves and nitric oxide. Eur. J. Pharmacol., 1999, 374:263-276.

[19] Sibilia, V.; Rindi, G.; Pagani, F. et al. Ghrelin protects against ethanolinduced gastric ulcers in rats: studies on the mechanisms of action. Endocrinology, 2003, 144: 353-9.

[20] Brzozowski, T., Konturek, P.C.; Konturek, S.J.; Kwiecien, S.; Drozdowicz D.; Bielanski, W.; Pajdo, R.; Ptak, A.; Nikiforuk, A.; Pawlik, W.W.; Hahn, E.G. Exogenous and endogenous ghrelin in gastroprotection against stressinduced gastric damage. Reg. Pept., 2004, 120: 39-51.

[21] Brzozowski, T.; Konturek, P.C.; Sliwowski, Z.; Pajdo, R.; Drozdowicz, D. Kwiecień, S.; Burnat, G.; Konturek, S.J.; Pawlik, W.W. Prostaglandin/cyclooxygenase pathway in ghrelin-induced gastroprotection against ischemia-reperfusion injury. J. Pharmacol. Exp. Ther ., 2006,319, 1:477-87.

[22] Tigerstedt, R.; Bergman, P.G. Niere und Kreislauf. Scand. Arch. Physiol., 1898, 4, 223-271.

[23] Skrbic, R.; Igic, R.; Seven decades of angiotensin (1939-2009). Peptides, 2009, 30, 1945-1950.

[24] Griendling, K.K.; Lasse`gue, B.; Alexander, R.W. Angiotensin receptors and their therapeutic implications. Annu. Rev. Pharmacol. Toxicol., 1996, 36, 281-306.

[25] Paul, M.; Poyan, Mehr, A.; Kreutz. R.; Physiology of local renin-angiotensin systems. Physio.l Rev., 2006, 86,3,747-803.

[26] Heinemann, A.; Sattler, V.; Jocic, M.; Wienen, W.; Holzer, P. Effect of angiotensin II and telmisartan, an angiotensin1 receptor antagonist, on gastric mucosal blood flow. Aliment. Pharmacol. Ther. 1999, 13, 347-355.

[27] Lavoie, J.L.; Sigmund, C.D. Minireview: overview of the renin-angiotensin system-an endocrine and paracrine system. Endocrinology, 2003, 144,6, 2179-2183.

[28] Suzuki, Y.; Ruiz-Ortega, M.; Lorenzo, O.; Ruperez, M.; Esteban, V.; Egido, J. Inflammation and angiotensin II. Int. J. Biochem. Cell. Biol .,2003, 35,6, 881-900.

[29] Deshayes, F.; Nahmias, C. Angiotensin receptors: a new role in cancer? Trends. Endocrinol. Metab., 2005, 16,7, 293-299.

[30] Ishiyama, Y.; Gallagher, P.E.; Averill, D.B.; Tallant, E.A.; Brosnihan, K.B.; Ferrario, C.M.; Upregulation of angiotensin converting enzyme 2 after myocardial infarction by blockade of angiotensin II receptors. Hypertension, 2004, 43,5. 970-976.

[31] Xu, F.; Mao, C.; Rui, C.; Xu, Z.; Zhang, L. Cardiovascular Effects of Losartan and Its Relevant Clinical Application. Curr. Med. Chem., 2009, 13. Saavedra, J.M.; Sanchez - Lemus E.; Benicky, J. Blockade of brain angiotensin II $\mathrm{AT}_{1}$ receptors ameliorates stress, anxiety, brain inflammation and ischemia: therapeutic implications. Psychoendocrinology, 2011, 36, 118.

[33] Kaparianos, A.; Argyropoulou, E. Local Renin-Angiotensin II Systems, Angiotensin-Converting Enzyme and its Homologue ACE2: Their Potential Role in the Pathogenesis of Chronic Obstructive Pulmonary Diseases, Pulmonary Hypertension and Acute Respiratory Distress Syndrome. Curr. Med. Chem. 2011, 14.

[34] Lee, M.;A, Bohm, M.; Paul, M.; Ganten, D. Tissue renin angiotensin systems. Their role in cardiovascular disease. Circulation, 1993, 87, 5, 13. 
[35] Sechi, L.A.; Valentin, J.P.; Griffin, C.A.; Schambelan, M. Autoradiographic characterization of angiotensin II receptor subtypes in rat intestine. Am. J. Physio.l Gastrointest. Liver. Physiol., 1993, 265, G21-G27.

[36] Bregonzio, C.; Armando, I.; Ando, H. et al. Anti-inflammatory effects of angiotensin II AT1 receptor antagonism prevent stress-induced gastric injury. Am. J. Physiol.Gastrointest. Live.r Physiol., 2003, 285:G414.

[37] Nakagiri, A.; Sunamoto, M.; Murakami, M. Angiotensin AT1 receptor blockers suppress ischemia/reperfusion-induced gastric injury in rats. Inflammopharmacology, 2007, 15,4,171-174

[38] Okuda, T.; Yoshida, N.; Takagi, T.; Handa, O.; Kokura, S.; Ichikawa, H.; Naito, Y.; Yoshikawa, T. CV-11974, angiotensin II type I receptor antagonist, reduces the severity of indomethacin-induced rat enteritis. Dig. Dis. Sci., 2008, 53,3, 657-663.

[39] Riaz, A,A.; Wang, Y.; Schramm, R. et al. Role of angiotensin II in ischemia/reperfusion-induced leukocyte-endothelium interactions in the colon. Faseb. J. 2004,18,881.

[40] Takagi, T.; Yoshida, N.; Isozaki, Y. et al. CV-11974, angiotensin II type I receptor antagonist, protects against ischemia-reperfusion injury of the small intestine in rats. Eur. J. Pharmacol. 2006, 535,283.

[41] Sendur, R.; Biernat, R.; Pawlik, M.; Obuchowicz, R.; Pawlik, W.W. Role of angiotensin 1-7 in the mediation of gastric circulatory and protective action angiotensin converting enzyme inhibitor. Faseb J., 2005, 19, 4, A74.

[42] Brzozowski, T.; Konturek,; P,C.; Konturek, S.J, et al. Expression of cyclooxygenase (COX)-1 and COX-2 in adaptive cytoprotection induced by mild stress. J. Physiol. Paris., 2000, 94:83.

[43] Brzozowski, T.; Konturek, P.C.; Pajdo, R. et al. Physiological mediators in nonsteroidal anti-inflammatory drugs (NSAIDs)-induced impairment of gastric mucosal defense and adaptation. Focus on nitric oxide and lipoxins. $J$. Physiol. Pharmacol., 2008, 59,2, 89 .

[44] Senay, C.E.; Levine, R.J. Synergism between cold and restraint for rapid production of stress ulcer in rats. Proc. Soc. Exp. Biol. Med., 1967, 124, $1221-1223$

[45] Jezova, D.; Ochedalski, T.; Kiss, A.; Aguilera, G. Brain angiotensin II modulates sympathoadrenal and hypothalamic pituitary adrenocortical activation during stress. J. Neuroendocrinol., 1998, 10, 67-72.

[46] Suzuki, Y.; Ruiz-Ortega, M.; Lorenzo, O. et al. Inflammation and angiotensin II. Int. J. Biochem. Cell. Biol., 2003, 35,881.

[47] Ruiz-Ortega, M.; Lorenzo, O.; Suzuki, Y. et al. Proinflammatory actions of angiotensins. Cur. Opin. Nephrol. Hypertens., 2001, 10:321.

[48] Marchesi, C. ; Paradis, P. ; Schiffrin, E.L. Role of the renin-angiotensin system in vascular inflammation. Trends. Pharmacol. Sci., 2008, 29:367.

[49] Nishimura, Y.; Ito, T.; Hoe, K.L.; Saavedra, J.M. Chronic peripheral administration of the angiotensin II AT1 receptor antagonist candesartan blocks brain AT1 receptors. Brain. Res., 2000, 871: 29-38

[50] Zhang, Y.M.; Wei, E.Q.; Hu. X. et al. The role of nuclear factor- $\kappa \mathrm{B}$ in the effect of angiotensin II in the paraventricular nucleus in protecting the gastric mucosa from ischemia-reperfusion injury in rats. J. Gastroenterol., 2008, 43:687.

[51] Gemici, B.; Tan, R.; Ongut, G.; Izgut - Uysal N. Expressions of inducible nitric oxide synthase and cyclooxygenase -2 in gastric ischemia reperfusion: role of angiotensin II. J. Surg. Res., 2009, 6, 1-8.

[52] Ito, T.; Yamakawa, H.; Bregonzio, C.; Terrón, J.A.; Falco' n-Neri, A.; Saavedra, J.M.; Protection against ischemia and improvement of cerebral blood flow in genetically hypertensive rats by chronic pretreatment with an angiotensin II AT1 antagonist. Stroke, 2002, 33, 2297-2303.

[53] Carl-McGrath, S.; Grantzdorffer, I.; Lendeckel, U.; Ebert, M.P.; Rocken, C. Angiotensin II - generating enzymes, angiotensin-converting enzyme (ACE) and mast cell chymase (CMA1), in gastric inflammation may be regulated by H.pylori and associated cytokines. Pathology, 2009, 41, 419-427.

[54] Hasegawa, G.; Fukui, M.; Hosada, H.; Asano, M.; Harusato, I.; Tanaka, M.; Shiraishi, E.; Senmaru, T.; Sakabe, K.; Yamasaki, M.; Kitawaki, J.; Fujinami, A.; Ohta, M.; Obayashi, H.; Nakamura, N. Telmisartan, an angiotensin II type 1 receptor blocker, prevents the development of diabetes in male Spont aneously Diabetic Torii rats. Eur. J. Pharmacol., 2009, 605, 164-169.

[55] Cai, H.; Griendling, K.K.; Harrison, D.G. The vascular NAD(P)H oxidases as therapeutic targets in cardiovascular diseases. Trends. Pharmacol. Sci., 2003, 24:,471-478.

[56] Nakagiri, A..; Sunamoto, M.;Takeuchi, K.; Murakami, M. Evidence for the involvement of NADPH oxidase in ischemia/reperfusion-induced gastric damage via angiotensin II. J. Physiol. Pharmacol., 2010, 61, 2, 171-9.

[57] Gao, Y.; Zhou, S.; Wen, J.; Huang, M.; Xu, A. Mechanism of the antiulcerogenic effect of Ganoderma lucidum polysaccharides on indomethacin-induced lesions in the rat. Life Sci., 2002, 72, 731-745.

Zhang, X.; Tajima, K.; Kageyama, K.; Kyoi, T. Irsogladine maleate suppresses indomethacin-induced elevation of proinflammatory cytokines and gastric injury in rats. World J. Gastroenterol., 2008, 14, 4784-4790.

[59] Benson, S.C.; Pershadsingh, H.A.; Ho, C.I, Chittiboyina A, Desai P, Pravenec M, Qi N, Wang J, Avery MA, Kurtz TW. Identification of telmisartan as a unique angiotensin II receptor antagonist with selective PPAR $\gamma$-modulating activity. Hypertension, 2004, 43, 993-1002.

[60] Nakamura, T.; Keep, R.F.; Hua, Y. Hoff, J.T.; Xi, G. Oxidative DNA injury after experimental intracerebral hemorrhage. Brain Res., 2005, 1039-36.
[61] Blessing, E; Preusch, M; Kranzhöfer, R; Kinscherf, R ; Marx, N Rosenfeld, M.E.; Isermann, B.; Weber, C.M.; Kreuzer. J.; GräJ, Katus, H.A.; Bea, F. Anti-atherosclerotic properties of telmisartan in advanced atherosclerotic lesions in apolipoprotein E deficient mice. Atherosclerosis, 2008, 199, 295-303.

[62] Morsy, M.A.; Ashour, O.M.; Fouad, A.A.; Abdel-Gaber, S.A. Gastroprotective effects of the insulin sensitizers, rosiglitazone and metformin, in indomethacin-induced gastric ulcer in type 2 diabetic rats. Clin. Exp. Pharmacol. Physiol ., 2010, 37, 173-177.

[63] Jung, K.H.; Chu, K.; Lee, S.T.; Kim. S.J.; Song, E.C.; Kim, E.H.; Park, D.K ; Sinn, D.I.; Kim, J.M.; Kim, M.; Roh, J.K. Blockade of AT1 receptor reduces apoptosis, inflammation, and oxidative stress in normotensive rats with intracerebral hemorrhage. J. Pharmacol. Exp. Ther., 2007, 322, 1051-1058.

[64] Kaschina, E.; Schrader, F.; Sommerfeld, M.; Kemnitz, U.R.; Grzesiak, A Krikov, M.; Unger, T. Telmisartan prevents aneurysm progression in the rat by inhibiting proteolysis, apoptosis and inflammation. J. Hypertens., 2008 , 26, 2361-2373.

Hallersund, P; Helander, H.F; Casselbrant, A; Edebo, A.; Fandriks, L; Elfvin, A. Angiotensin II receptor expression and relation to Helicobacter pylori-infection in the stomach of the Mongolian gerbil. BMC Gastroenterol., 2010, 10, 3 .

Hallersund, P.; Elfvin, A.; Helander, H.F.; Fasidriks, L. The expression of rennin -angiotensin system components in the human gastric mucosa. $J$. Renin. Ang. Aldost. Syst., 2010, 12, 54-64.

[67] Rasini, E.; Cosentino, M.; Marino, F.; Legnaro, M.; Ferrari, M.; Guasti, L.; Venco, A.; Lecchini, S. Angiotensin II type 1 receptor expression on human leukocyte subsets: a flow cytometric and RT-PCR study. Regul. Pept., 2006, 134, 2-3, 69-74.

[68] Elfvin, A.; Edebo, A.; Bolin, I.; Fandriks, L. Quantitative measurement of nitric oxide and hydrogen peroxide in Helicobacter pylori-infected Mongolian gerbils in vivo. Scand. J. Gastroenterol., 2007, 42, 10, 11751181 .

[69] Huang, W.; Yu, L.F.; Zhong, J. et al. Stat3 is involved in angiotensin IIinduced expression of MMP2 in gastric cancer cells. Dig. Dis. Sci ., 2009, 54, 2056-2062

[70] Sugimoto, M.; Furuta, T.; Shirai, N. et al. Role of angiotensinogen gene polymorphism on Helicobacter pylori infection-related gastric cancer risk in Japanese. Carcinogenesis, 2007, 28, 2036-2040.

[71] Soares de Moura, R.; Resende, A.C.; Emiliano, A.F.; et. al. The role of bradykinin, $\mathrm{AT}_{2}$ and angiotensin 1-7 receptors in the EDRF - dependent vasodilator effect of angiotensin II on the isolated mesenteric vascular bed of the rat. Br. J. Pharmacol., 2004, 141, 860-6.

[72] Cosentino, F.; Savoia, C.; De Paolis, P. et. al. Angiotensin II type 2 receptors contribute to vascular responses in spontaneously hypertensive rats treated with angiotensin II type I receptor antagonists. Am. J. Hypertens., 2005, 18, 493-9.

[73] You, D.; Loufrani, L.; Baron, C.; Levy, B.I.; Widdop, R.E.; Henrion, D High blood pressure reduction reverses angiotensin II type 2 receptor mediated vasoconstriction into vasodilation in spontaneously hypertensive rats. Circulation, 2005, 111, 1006-11.

[74] Meng, W.; Busija, D.W. Comparative effects of angiotensin - (1-7) and angiotensin II on piglet pial arterioles. Stroke, 1993, 24, 2041-4.

[75] Ren, Y.; Garvin, J.L.; Carretero, O.A. The vasodilator action of angiotensin(1-7) on isolated rabbit afferent arterioles. Hypertension, 2002, 39, 799-802.

[76] Santos, R.A.; Simoes e Silva, A.C.; Maric, C. et. al. Angiotensin-(1-7) is an endogenous ligand for the $\mathrm{G}$ protein-coupled receptor Mas. Proc. Natl Acad. Sci., 2003, 100, 8258-63.

[77] Oliveira, M.A.; Fortes, Z.B.; Santos, R.A.; Kosla, M.C.; De Carvalho, M.H Synergistic effect of angiotensin (1-7) on bradykinin arteriolar dilation in vivo. Peptides, 1999, 20, 1195-201.

[78] Bernstein, K.E. Views of the renin-angiotensin system: brilling, mimsy, and slithy tove. Hypertension, 2006, 47,3, 509-514.

[79] Ferrario, C.M.; Chappell, M.C. Novel angiotensin peptides. Cell. Mol. Life Sci., 2004, 61,21, 2720-2727.

[80] Varagic, J.; Trask, A.J.; Jessup, J.A.; Chappell, M.C.; Ferrario, C.M. New angiotensins. J. Mol. Med., 2008, 86,6, 663-671.

[81] Kramkowski, K., Mogielnicki, A., Buczko, W. The physiological significance of the alternative pathways of angiotensin II production. $J$. Physiol. Pharmacol., 2006, 57,4, 529-539.

[82] Miyazaki, M.; Takai, S. Tissue angiotensin II generating system by angiotensin-converting enzyme and chymase. J. Pharmacol Sci., 2006, $100,5,391-397$.

[83] Wolf, G. Novel aspects of the renin-angiotensin-aldosteronesystem. Front. Biosci., 2008, 13, 4993-5005.

[84] Nonotte, I.; Laliberte, M.F.; Duperray, C.; Hollande, F.; Bali, J.P.; Laliberte, F. et al. Expression of angiotensin I converting enzyme mRNA in rabbit gastric epithelial cells. Mol. Cell Endocrino.,l 1993, 92,2,167-174.

[85] Pawlik, M.W.; Sendur, R.; Biernat, J.; Brzozowski, T.; Konturek, S.; Pawlik $\mathrm{W} . \mathrm{W}$. Involvement of nitric oxide and prostaglandins in the angiotensin 1-7 induced acceleration of the healing of experimental gastric ulcers. Gastroenterology, 2010, 138, 5, 1, S131.

[86] Cullen, J.J.; Ephgrave, K.S.; Kleiman-Wexler, R.L.; Broadhurst, K. Angiotensin-converting enzyme inhibition, kinins, and stress ulceration. $\mathrm{Cur}$ Surg. 1990, 47,6, 452-454. 
[87] Ender, F.; Labancz, T.; Rosivall, L. Protective effects of the inhibition of the renin-angiotensin system against gastric mucosal lesions induced by coldrestraint in the rat. Acta Physiol. Hung., 1993, 81,1,13-18.

[88] Kincaid, E.H.; Miller, P.R.; Meredith, J.W.; Chang, M.C. Enalaprilat improves gut perfusion in critically injured patients. Shock, 1998, 9,2, 79-83.

[89] Nonotte, I.; Laliberte, M.F.; Gannoun-Zaki, L.; Bali, J.P.; Chevillard, C.; Laliberte, F. Localization of angiotensin converting enzyme (ACE) mRNA in rabbit gastric mucosa by in situ hybridization. J. Histochem. Cytochem., 1994, 42,2,197-201.

[90] Bujak-Gizycka, B; Madej, J.; Wolkow, P.P.; Olszanecki, R.; Drabik, L.; Rutowski, J. et al. Measurement of angiotensin metabolites in organ bath and cell culture experiments by liquid chromatography - electrospray ionization mass spectrometry (LC-ESI-MS). J. Physiol. Pharmacol., 2007, 58,3, 529540 .

[91] Olszanecki, R.; Bujak-Gizycka, B.; Madej, J.; Suski, M.; Wolkow, P.P.; Jawien, J. et al. Kaempferol, but not resveratrol inhibits angiotensin converting enzyme. J. Physiol. Pharmacol., 2008; 59,2, 387-392.

[92] Mise, S.; Tonkic, A.; Pesutic, V.; Tonkic, M; Capkun, V.; Batelja, L.; Blagaic, AB.; Kokic, N.; Zoricic, I.; Seifert, D.; Anic, T.; Seiwerth, S.;
Sikiric, P. The presentation and organization of adaptive cytoprotection in the rat stomach, duodenum, and colon. Dedicated to André Robert the founder of the concept of cytoprotection and adaptive cytoprotection. Med Sci Monit., 2006, 12, BR146-53.

[93] Bedekovic, V.; Mise, S.; Anic, T.; Staresinic, M.; Gjurasin, M.; Kopljar, M.; Kalogjera, L.; Davis, P.; Blagaic, A.; Batelja, L.; Seiwerth, S.; Sikiric, P. Different effect of antiulcer agents on rat cysteamine-induced duodenal ulcer after sialoadenectomy, but not gastrectomy. Eur J Pharmacol., 2003, 47, 7380 .

[94] Haulica, I.; Bild, W.; Serban, D.N. Angiotensin peptides and their pleiotropic actions. J. Renin. Angiotensin. Aldosterone. Syst., 2005; 6,3, 121-131.

[95] Chappel, M.C.; Ferrario, C.M. ACE and ACE2: their role to balance the expression of angiotensin II and angiotensin-(1-7). Kidney Int., 2006, 70,1, 8 10.

[96] Chappell, M.C. Emerging evidence for a functional angiotensin-converting enzyme 2-angiotensin-(1-7)-MAS receptor axis: more than regulation of blood pressure? Hypertension, 2007, 50,4, 596-599. 